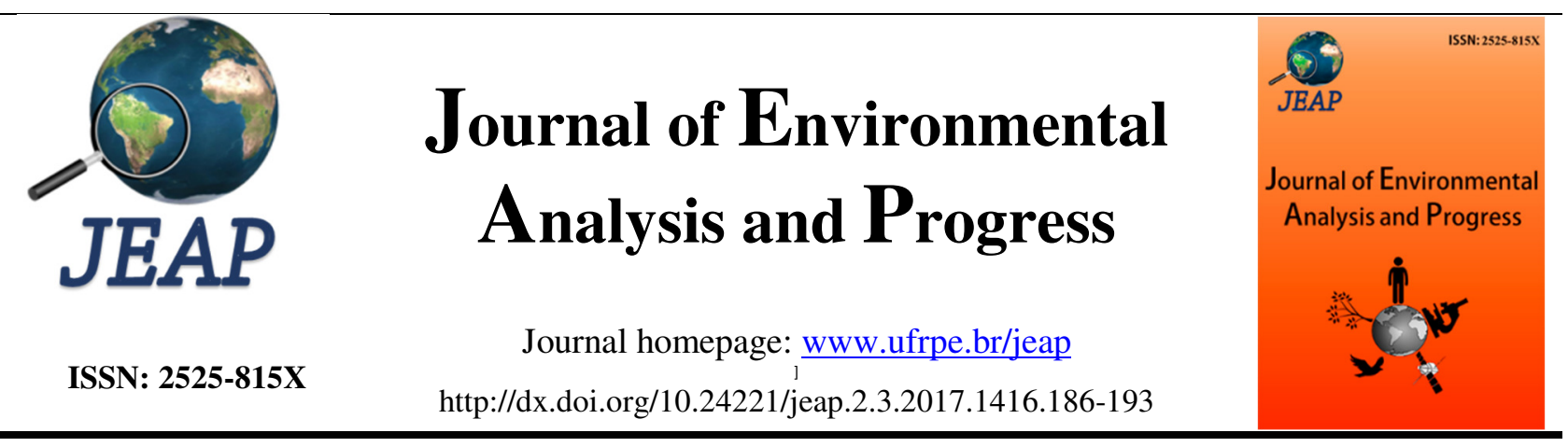

\title{
Estimativas de perda de solo por erosão hídrica para o município de Serra Talhada, PE
}

\section{Estimates of loss of soil by water erosion to the municipality of Serra Talhada, PE}

Alexandre Maniçoba da Rosa Ferraz Jardim ${ }^{a^{*}}$, George do Nascimento Araújo Júnior ${ }^{a}$, Marcelo José da Silva ${ }^{\mathrm{a}}$, José Edson Florentino de Morais ${ }^{\mathrm{b}}$, Thieres George Freire da Silva ${ }^{\mathrm{a}}$

a Unidade Acadêmica de Serra Talhada, Universidade Federal Rural de Pernambuco, Av. Gregório Ferraz Nogueira, s/n, José Tomé de Souza Ramos, Serra Talhada, Pernambuco, Brasil. CEP: 56909-535. E-mail: alexandremrfj@gmail.com, georgejunior91.gj@gmail.com, marcelosilvaagr@gmail.com, thieres_freire@yahoo.com.br. *Autor correspondente.

b Departamento de Engenharia Agrícola, Universidade Federal Rural de Pernambuco, Rua Dom Manoel de Medeiros, s/n, Dois Irmãos, Recife, Pernambuco, Brasil. CEP: 52171-900. E-mail: joseedson50@gmail.com.

\section{A R T I C L E I N F O}

Recebido 25 Jun 2017

Aceito 02 Jul 2017

Publicado 31 Jul 2017

\begin{abstract}
A B S T R A C T
Changes in ecosystems in degraded environments increase annually due to the need for food production. A quantification of soil losses due to water erosion in agricultural areas is fundamental. In this sense, the objective was to estimate soil losses by water erosion in different periods of rainfall series in two types of soil in the municipality of Serra Talhada, State of Pernambuco. The study was made considering the data of two areas, one with a Haplic Planosol and the other with a Red-Yellow Acrisol. The areas were composed by an experimental plot of $100 \mathrm{~m}$ ramp length, with slope of 5\% for Planosol and 3\% for Acrisol. Soil loss was estimated through the USLE in the period from 1996 to 2015, and is subdivided into four periods: Period I (1996-2015), Period II (2001-2015), Period III (2006-2015) and Period IV (2011 -2015). The values considered for soil management (C) and soil support practices $(\mathrm{P})$ were 0.080 and 0.5 , respectively. Rainfall for the series evaluated (1996 to 2015) presented an average of $600.62 \mathrm{~mm}$. The erosion indexes $\left(\mathrm{EI}_{\mathrm{m}}\right)$ of Haplic Planosol and Acrisol were considered weak. The rainfall $(\mathrm{R})$ erosivity factor was $420.89 \mathrm{MJ} . \mathrm{mm} \cdot \mathrm{ha}^{-1} \cdot \mathrm{h}^{-1}$.year ${ }^{-1}$, resulting in a soil loss of 5.04 and 2.75 ${\mathrm{Mg} . \mathrm{ha}^{-1} \text {.year }}^{-1}$, in the Period II. Thus, it was concluded that Haplic Planosol is more susceptible to soil loss than the Red-Yellow Acrisol under the climatology of the municipality of Serra Talhada.
\end{abstract}

Keywords: Rainfall, erodibility, Planosol, Acrisol.

\section{R E S U M O}

Alterações de ecossistemas naturais em ambientes degradados aumentam anualmente devido a necessidade de produção de alimentos. A quantificação das perdas de solo por erosão hídrica em áreas agrícolas é de fundamental importância. Nesse sentido, objetivou-se estimar as perdas de solo por erosão hídrica em diferentes períodos de séries provisórias pluviais em dois tipos de solo no município de Serra Talhada, PE. O estudo foi realizado considerando os dados de duas áreas, uma com um Planossolo Háplico e outro com um Argissolo Vermelho-Amarelo. As áreas eram compostas por uma parcela experimental de $100 \mathrm{~m}$ de comprimento de rampa, com declividade de 5\% para o Planossolo e de 3\% para o Argissolo. A perda de solo foi estimada através da USLE no intervalo de 1996 a 2015, sendo subdividido em quatro períodos: Período I (1996-2015), Período II (2001-2015), Período III (2006-2015) e Período IV (2011-2015). Os valores considerados para o manejo do solo (C) e para 
práticas de suporte do solo (P) foram de 0,080 e 0,5 , respectivamente. A precipitação pluvial para a série avaliada (1996 a 2015) apresentou média de 600,62 mm. Os índices de erosão $\left(\mathrm{EI}_{\mathrm{m}}\right)$ do Planossolo e Argissolo foram considerados fracos. $\mathrm{O}$ fator de erosividade da chuva (R) foi de $420,89 \mathrm{MJ} \cdot \mathrm{mm} \cdot \mathrm{ha}^{-1} \cdot \mathrm{h}^{-1} \cdot \mathrm{ano}^{-1}$, acarretando em uma perda de solo de 5,04 e 2,75 Mg.ha ${ }^{-1}$. no $^{-1}$, no Período II. Dessa forma, concluiu-se que o Planossolo Háplico é mais suscetível a perda de solo que o Argissolo Vermelho-Amarelo sob a climatologia do município de Serra Talhada.

Palavras-Chave: Precipitação pluvial, erodibilidade, Planossolo, Argissolo.

\section{Introdução}

O mal planejamento do uso de terras agrícolas para a exploração de alimentos, vem crescendo anualmente, ocasionando a transformação de ecossistemas naturais em ambientes degradados. Por décadas, o homem tem praticado a extração de recursos naturais modificando os ecossistemas. Em virtude dessa ação antrópica inadequada, boa parte dessas terras vêm diminuindo sua capacidade produtiva e causando danos irreversíveis devido à expansão da degradação do solo (Fiorio et al., 2016; Barros et al., 2016).

Em regiões semiáridas, os processos de degradação dos solos são mais agravantes devido à pouca profundidade e pedregosidade, que os tornam mais vulneráveis (Guimarães, Valladares \& Martins, 2016). Nessas regiões, práticas conservacionistas e mapeamento das áreas auxiliam na conservação do meio ambiente e manutenção das características do solo, minimizando as perdas de solo e os impactos sobre o mesmo (Valladares et al., 2012).

$\mathrm{O}$ escoamento superficial proveniente da precipitação pluvial é um dos fatores considerados de extrema importância no processo de degradação do solo, pois causam os maiores prejuízos devido a erosão hídrica (Bertoni \& Lombardi Neto, 2008; Guerra, Silva \& Botelho, 2009). As descargas pluviais proporcionam a erosão laminar, que é caracterizada por carrear sedimentos e partículas de solos, tornando-se pouco perceptível e, assim de maior periculosidade (Bertoni \& Lombardi Neto, 2012).

O entendimento e a quantificação das perdas de solo por erosão hídrica em áreas agrícolas são de fundamental importância e pode ser realizada pela utilização de métodos indiretos como os modelos empíricos. Um desses modelos bastante utilizados é a Equação Universal de Perda de Solo (EUPS), também conhecida como Universal Soil Loss Equation (USLE). É um método multiplicativo de ótima precisão que leva em consideração a precipitação pluvial do local, tipo de solo, morfologia do terreno, sistema de cultivo e as práticas de gestão (Wischmeier \& Smith, 1978; Bertoni \& Lombardi Neto, 2012).

Diante do exposto, objetivou-se estimar as perdas de solo por erosão hídrica em diferentes períodos de séries provisórias pluviais, através do método da USLE, em dois tipos de solo no município de Serra Talhada, PE.

\section{Material e Métodos}

O estudo foi realizado no município de Serra Talhada, PE (Latitude: 7 ${ }^{\circ} 56^{\prime} 20^{\prime \prime}$ S; Longitude: 38 17'31" O e Altitude: $498 \mathrm{~m}$ ), microrregião do Vale do Pajeú, Mesorregião do Sertão Pernambucano, em duas áreas distintas, para dois tipos de solo, caracterizados como um Planossolo Háplico e um Argissolo VermelhoAmarelo (Santos et al., 2013).

A perda de solo foi estimada no intervalo de 1996 a 2015, sendo subdividido em quatro períodos: Período I (1996-2015), Período II (20012015), Período III (2006-2015) e Período IV (20112015). Os dados foram obtidos através da Agência Pernambucana de Águas e Clima (www.apac.pe.gov.br), referentes ao Posto de Código 13.

A área do presente estudo era composta por uma parcela experimental de $100 \mathrm{~m}$ de comprimento de rampa, com declividade de 5\% para o Planossolo Háplico e de 3\% para o Argissolo Vermelho-Amarelo (Figura 1), apresentando-se como solos cultivados por culturas anuais e perenes.

O clima da região, de acordo com a classificação climática de Köppen, é do tipo BSwh' (compreendendo os meses mais quentes com maiores índices de precipitação pluvial e os meses mais frios com seca) (Alvares et al., 2013), com $24,8^{\circ} \mathrm{C}$ de temperatura média do ar anual, 642,1 $\mathrm{mm}$ de precipitação pluvial média anual, $62,5 \%$ de umidade relativa do ar, acarretando em uma demanda atmosférica de $1.800 \mathrm{~mm}^{-a_{n} \mathrm{~s}^{-1} \mathrm{e}}$ ocorrendo um déficit atmosférico de 1.143 mm.ano ${ }^{-1}$ (Silva et al., 2015). 


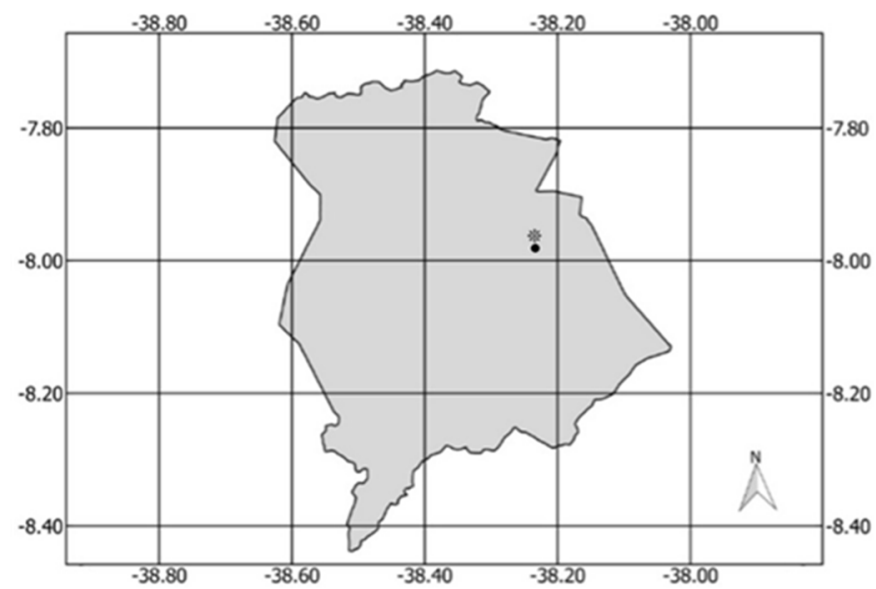

Figura 1. Localização geográfica dos pontos de estudo dos perfis de solos, para um Planossolo Háplico, * = Latitude: $7^{\circ} 95^{\prime} \mathrm{S}$; Longitude: $38^{\circ} 29^{\prime}$ O e um Argissolo Vermelho-Amarelo, $\bullet=$ Latitude: $7^{\circ} 93$ ' S; Longitude: $38^{\circ} 29^{\prime}$ O, no município de Serra Talhada, PE, região do Semiárido brasileiro. Fonte: Jardim et al. (2017).

Para a estimativa das perdas anuais médias de solo, foi utilizado o modelo matemático proposto por Wischmeier \& Smith (1978), conforme a Equação 1:

$$
\mathrm{A}=\mathrm{R} \cdot \mathrm{K} \cdot \mathrm{LS} \cdot \mathrm{C} \cdot \mathrm{P}
$$

onde $\mathrm{A}=$ perda de solo média anual $\left(\mathrm{Mg}_{\mathrm{g}} \mathrm{ha}^{-1} \cdot \mathrm{ano}^{-}\right.$ ${ }^{1}$ ), $\mathrm{R}=$ fator de erosividade da chuva (MJ.mm.ha' $\left.{ }^{1} \cdot \mathrm{h}^{-1} \cdot \mathrm{ano}^{-1}\right), \mathrm{K}=$ fator de erodibilidade do solo $\left(\mathrm{Mg} \cdot \mathrm{ha}^{-1} \cdot \mathrm{MJ}^{-1} \cdot \mathrm{mm}^{-1}\right), \quad \mathrm{LS}=$ fator topográfico (adimensional), em função do fator de declividade da vertente (\%) e o comprimento da rampa (m), C $=$ fator de uso e manejo do solo (adimensional, variando de 0,001 a 1,0 ) e $\mathrm{P}=$ práticas de suporte ou de conservação do solo em áreas agrícolas (adimensional, variando de 0,3 a 1,0).

Para a determinação do índice de erosão médio do solo $\left(\mathrm{EI}_{\mathrm{m}}\right)$, foram coletados dados de precipitação pluvial, mensal e anual do local e aplicada a Equação 2, proposta por Bertoni \& Lombardi Neto (2012):

$$
\mathrm{EI}_{\mathrm{m}}=6,886\left(\frac{\mathrm{P}_{\mathrm{m}}^{2}}{\mathrm{P}}\right)^{0,85}
$$

onde $\mathrm{EI}_{\mathrm{m}}=$ índice de erosão $\left(\mathrm{MJ} \cdot \mathrm{mm} \cdot \mathrm{h}^{-1} \cdot \mathrm{ha}^{-1}\right), \mathrm{P}_{\mathrm{m}}=$ precipitação pluvial média mensal $(\mathrm{mm})$ e $\mathrm{P}=$ precipitação pluvial média anual (mm).

A erosividade da chuva (também conhecida como fator R) levou em consideração o somatório do $\mathrm{EI}_{\mathrm{m}}$, para cada ano, conforme a Equação 3, proposta por Lombardi Neto \& Moldenhauer (1992):

$\mathrm{R}=\sum_{\mathrm{i}=1}^{\mathrm{n}} \mathrm{EI}$

onde $\mathrm{R}$ = fator de erosividade da chuva (MJ.mm.ha $\left.{ }^{1} \cdot \mathrm{h}^{-1} \cdot \mathrm{ano}^{-1}\right)$ e $\mathrm{EI}_{\mathrm{m}}=$ índice de erosão $\left(\mathrm{MJ} \cdot \mathrm{mm} \cdot \mathrm{h}^{-1} \cdot \mathrm{ha}\right.$ $\left.{ }^{1}\right)$.

$\mathrm{O}$ fator de erodibilidade do solo $(\mathrm{K})$ foi determinado, indiretamente, de acordo com a expressão de Bouyoucos, conforme a Equação 4 (Wischmeier \& Smith, 1978):

$$
\mathrm{K}=\left(\frac{0,00021 \cdot \mathrm{M}^{1,14}(12-\mathrm{a})}{100}\right) \Lambda \quad+\left(\frac{3,25(\mathrm{~b}-2)+3,3 \cdot 10^{-3}(\mathrm{c}-3)}{100}\right)
$$

onde $\mathrm{K}$ = fator de erodibilidade do solo (Mg.h.MJ ${ }^{-}$ $\left.{ }^{1} \cdot \mathrm{mm}^{-1}\right), \mathrm{M}=$ é obtido através da função [(\% silte + $\%$ areia fina) x (100 - \% argila)], a = é a \% matéria orgânica, $b=$ coeficiente relativo à estrutura do solo e c = é a classe de permeabilidade do solo.

Os componentes para a aplicação do modelo que determina o fator de erodibilidade do solo $(\mathrm{K})$, foram adquiridos através da análise físico-química dos dois solos na área de estudo, sendo para o Planossolo Háplico: 11,60\% de argila, $10,04 \%$ de silte, $26,62 \%$ de areia fina, $1,71 \%$ de matéria orgânico, $1,29 \mathrm{~kg} \cdot \mathrm{m}^{-3}$ de densidade do solo e pH 6,6 $\left(\mathrm{em} \mathrm{H}_{2} \mathrm{O}\right)$, e para o Argissolo VermelhoAmarelo: 6,37\% de argila, 25,25\% de silte, 68,36\% de areia fina, $1,31 \%$ de matéria orgânica, 1,53 $\mathrm{kg} \cdot \mathrm{m}^{-3}$ de densidade do solo e $\mathrm{pH} 6,5\left(\mathrm{em} \mathrm{H}_{2} \mathrm{O}\right)$, ambos a $0,20 \mathrm{~m}$ de profundidade. 
Os fatores topográficos em função do relevo (LS) foram estimados com base na Equação 5 (Wischmeier \& Smith, 1978):

$$
\mathrm{LS}=\frac{\sqrt{\mathrm{L}}}{100}\left(1,36+0,97 \cdot \mathrm{S}+0,1385 \cdot \mathrm{S}^{2}\right)
$$

onde LS = fator topográfico (adimensional), $\mathrm{L}=\mathrm{o}$ é comprimento da rampa (m) e $\mathrm{S}=$ declividade da vertente $(\%)$.

Os valores dos fatores de uso e manejo do solo (C), que está interligado no efeito da vegetação nas perdas de solo, foi de 0,080 , descrito para "plantações", e o fator de práticas de suporte do solo (P), que está ligado às práticas conservacionistas do solo no controle da erosão, foi de 0,5 , utilizado para "plantações"; esses coeficientes foram obtidos conforme Bertoni \& Lombardi Neto (2012). Todas as análises foram realizadas utilizando o software R (R Core Team, 2016).

\section{Resultados}

Na Figura 2 observam-se os valores da precipitação pluvial para o município de Serra Talhada, PE, durante os períodos do estudo.

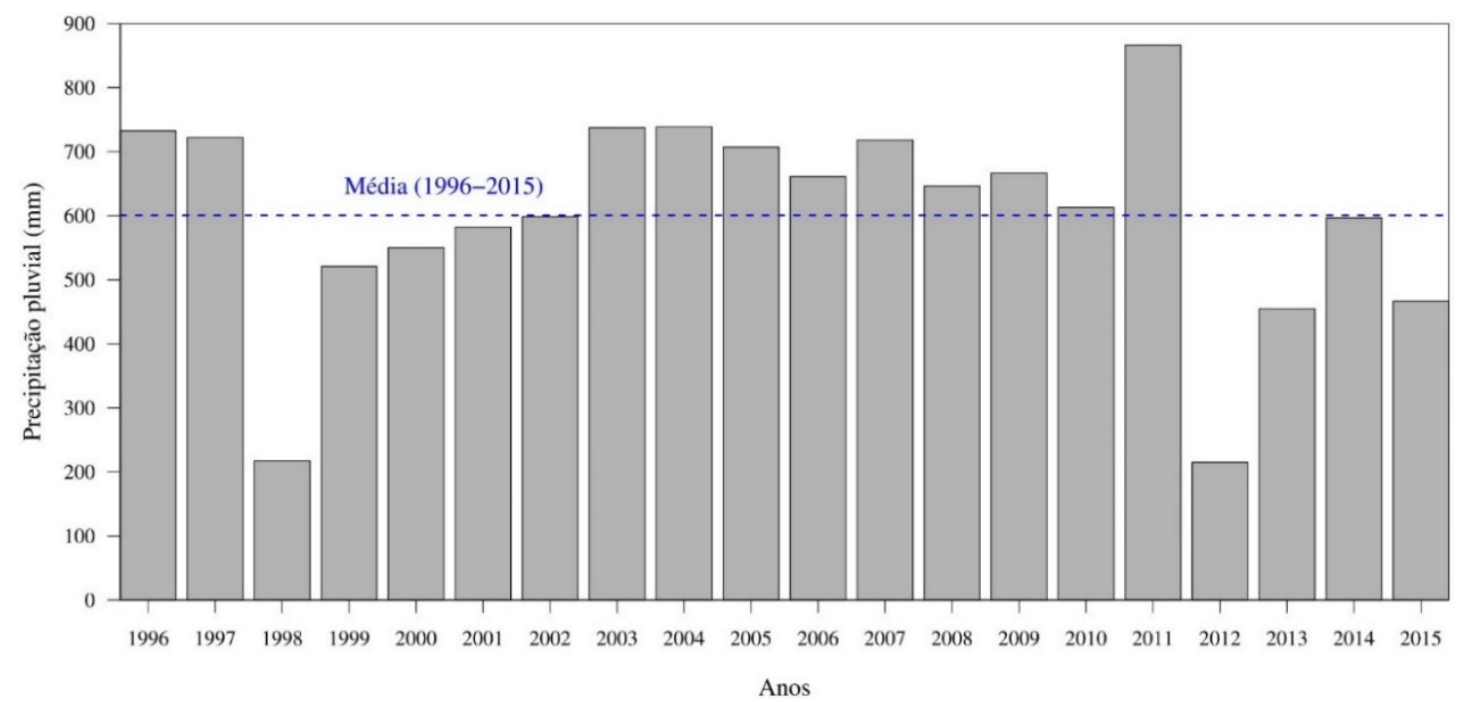

Figura 2. Médias de precipitação pluvial durante os anos de 1996 a 2015 para o município de Serra TalhadaPE, região do semiárido brasileiro. Fonte: Jardim et al. (2017).

Em virtude dos dados mensais das séries analisadas, os maiores eventos de precipitação em todos os períodos ocorreram nos meses de fevereiro a abril, correspondendo a 44,30\%. A precipitação pluvial dos períodos avaliados (1996 a 2015) apresentou média de 600,62 $\mathrm{mm}$.

Os resultados para os diferentes índices de erosão $\left(\mathrm{EI}_{\mathrm{m}}\right)$ encontrados durante o estudo para $\mathrm{o}$ Planossolo Háplico estão apresentados na Figura 3A. Esses valores subsidiaram informações

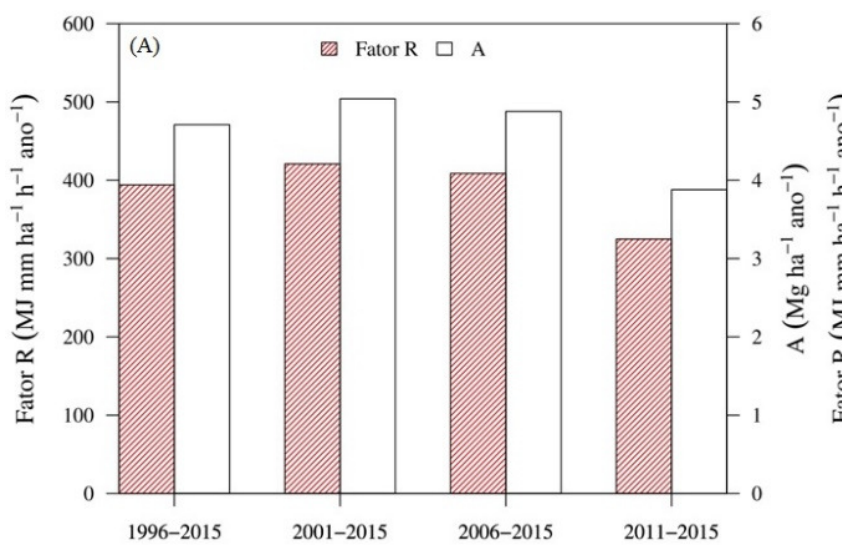

importantes para a determinação do fator de erosividade da chuva (R), que variaram de 324,99 a 420,89 MJ.mm.ha ${ }^{-1} \cdot h^{-1} \cdot$ ano $^{-1}$, nos períodos analisados, para o município de Serra Talhada, PE (Figura 3).

Devido à má distribuição dos eventos de precipitação pluvial da região, ao longo dos períodos, foram encontrados diferentes resultados para o fator $\mathrm{R}$ (variando de 393,92 a 420,89 MJ.mm.ha ${ }^{-1} \cdot h^{-1} \cdot$ ano $\left.^{-1}\right)$.

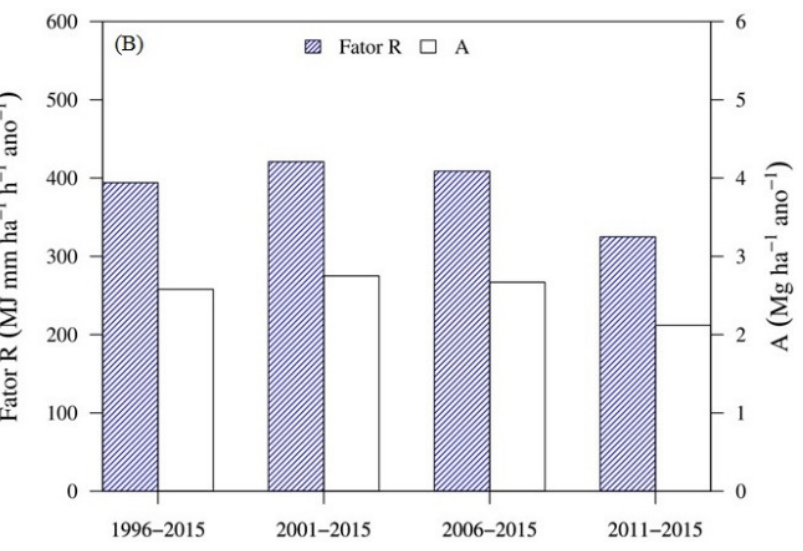


Figura 3. Valores médios dos fatores de erosividade da chuva: R (MJ.mm.ha $\left.{ }^{-1} \cdot \mathrm{h}^{-1} \cdot \mathrm{ano}^{-1}\right)$ e perda de solo; A (Mg.ha- ${ }^{-1}$ ano $^{-1}$ ) em cada período (1996-2015) estudado no Planossolo Háplico (A) e no Argissolo VermelhoAmarelo (B) para o município de Serra Talhada-PE, região do semiárido brasileiro. Fonte: Jardim et al. (2017).

O fator de erodibilidade do solo (K) nos períodos avaliados foi considerado constante, para ambos os solos, uma vez que as condições do solo foram as mesmas durante todo o período de avaliação.

Mannigel et al. (2002), em estudos sobre a erodibilidade do solo (K) no Estado de São Paulo, encontraram valores entre 0,0100 e 0,0466 Mg.h.MJ ${ }^{-1} \cdot \mathrm{mm}^{-1}$ para Argissolo VermelhoAmarelo e entre 0,0317 e 0,0088 Mg.h.MJ ${ }^{-1} \cdot \mathrm{mm}^{-1}$ para Planossolo. Em estudos realizados no Estado da Paraíba, com Planossolo Háplico e Argissolo Vermelho-Amarelo, Amaral (2016) encontrou resultados de erodibilidade do solo $(\mathrm{K})$ de 0,075 e 0,116 Mg.h.MJ ${ }^{-1} \cdot \mathrm{mm}^{-1}$, respectivamente, sendo inferiores aos resultados do presente estudo. Resultados similares também foram reportados por Silva \& Alvares (2005), estudando Argissolo Vermelho-Amarelo e Planossolo Háplico, na região do Estado de São Paulo, encontrando valores de 0,0425 e 0,0097 Mg.h.MJ ${ }^{-1} \cdot \mathrm{mm}^{-1}$, respectivamente.

A partir da obtenção dos parâmetros do fator $\mathrm{K}$ foram determinadas as perdas de solo para os quatro períodos (Figura $3 \mathrm{AB}$ ) através da USLE. A perda de solo no Período I (1996-2016) foi de 4,72 Mg.ha ${ }^{-1} \cdot$ ano $^{-1}$. Esse período apresentou uma perda de solo $21,34 \%$ maior do que o Período IV, que foi de 3,89 Mg.ha- ${ }^{-1} \cdot \mathrm{ano}^{-1}$.

$\mathrm{O}$ Argissolo Vermelho-Amarelo apresentou as maiores perdas de solo (A) durante o Período II (2001-2015), com 2,75 Mg.ha ${ }^{-1} \cdot$ ano $^{-1}$, seguido do Período III (2006-2015), com 2,67 Mg.ha ${ }^{-1} \cdot$ ano $^{-1}$ (Figura 3B). Porém, essas perdas de solo foram bem inferiores àquelas ocorridas no Planossolo Háplico. Isso pode estar associado às características físicas do Planossolo, ao maior teor de argila e às baixas concentrações de areia, sendo as mesmas mais favoráveis à erosão.

Os valores de perdas de solo encontrados nesse estudo, para o Planossolo, foram superiores aos reportados por Oliveira et al. (2008), também

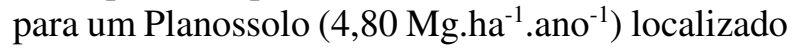
no município de Areia-PB, quando classificaram essa perda de solo como de baixa tolerância; em Argissolo as perdas foram de 7,03 Mg.ha ${ }^{-1}$. ano ${ }^{-1}$. Martins Filho et al. (2009) encontraram em um Argissolo Vermelho-Amarelo com 5,81 Mg.ha${ }^{1}$. ano $^{-1}$. Estes dois últimos autores encontraram valores superiores aos descritos nesse estudo para um Argissolo Vermelho-Amarelo.

\section{Discussão}

Os resultados encontrados apresentaram diferença dos meses caracterizando como chuvosos por Santos, Silva \& Montenegro (2010), que compreendem entre os meses de março a agosto, acarretando em maiores riscos de perdas de solo e água por erosão hídrica. De acordo com a Sectma (2006), 65\% dos eventos de precipitação pluvial desta região semiárida, estão concentrados nos meses de janeiro a abril.

Para Silva et al. (2010) de 60 a $70 \%$ os meses mais chuvosos, são de janeiro a abril, sendo em março a maior contribuição das águas. Esses resultados ficando bem próximo aos valores reportados por Silva et al. (2015) e Pereira et al. (2015) para essa região de Serra Talhada, PE (com 642,1 e $642 \mathrm{~mm} \cdot \mathrm{ano}^{-1}$, respectivamente).

Com relação ao índice de erosão $\left(\mathrm{EI}_{\mathrm{m}}\right)$, foram considerados valores fracos, conforme a classificação de Leprun (1983). Segundo Carvalho (2008), esses eventos também podem ser classificados como de baixa erosão. Albuquerque et al. (2005) encontraram índices de erosão, para um Argissolo Vermelho-Amarelo, no município de Sumé-PB, de 4.928 MJ.mm.h ${ }^{-1} \cdot \mathrm{ha}^{-1}$, com precipitação pluvial média de $695 \mathrm{~mm} \cdot \mathrm{ano}^{-1}$.

Segundo Santos, Silva \& Montenegro (2010), as variações desses eventos no tempo e no espaço é característico da região semiárida. Os eventos de precipitação pluvial são fatores físicos de grande influência na magnitude das perdas de solo em regiões como essas (Thomaz, 2009). A região Nordeste brasileira apresenta os valores mais baixos de erosividade, especificamente para o Estado de Pernambuco. O território brasileiro apresenta uma média observada para a erosividade variando de 1.672 a $22.452 \mathrm{Mj} \cdot \mathrm{mm} \cdot \mathrm{ha}^{-1} \cdot \mathrm{h}^{-1} \cdot \mathrm{ano}^{-1}$ (Oliveira, Wendland \& Nearing, 2012), dependendo da extensão territorial e do clima local.

Os valores encontrados no presente estudo, relativos ao fator $\mathrm{R}$, estão abaixo daqueles normalmente ocorridos no Brasil (Oliveira, Wendland \& Nearing, 2012), sendo também inferiores aos reportados por Campos Filho et al. (1992) para a região do Agreste do Estado de Pernambuco, onde encontraram valores superiores a 800 MJ.mm.ha ${ }^{-1} \cdot h^{-1} \cdot$ ano $^{-1}$ para solos do tipo Podzólico Vermelho-Amarelo. Para o Planossolo Háplico, esse valor foi de $0,2497 \mathrm{Mg}$.h.MJ ${ }^{-1} . \mathrm{mm}^{-1}$, que, segundo a classificação proposta por Leprun (1983) para a região Nordeste do Brasil, essa erodibilidade varia de fraca a média (sendo $\mathrm{K}$ de 
0,1 a $0,3 \mathrm{Mg} \cdot \mathrm{h} \cdot \mathrm{MJ}^{-1} \cdot \mathrm{mm}^{-1}$ ), para o Argissolo Vermelho-Amarelo foi de $0,7339 \mathrm{Mg} \cdot \mathrm{h} \cdot \mathrm{MJ}^{-1} \cdot \mathrm{mm}^{-1}$, caracterizando uma erodibilidade forte $(\mathrm{K}>0,5$ Mg.h.MJJ-1 $\left.\mathrm{mm}^{-1}\right)$.

$\mathrm{O}$ resultado encontrado para o fator de erodibilidade do solo (K) no presente estudo foi superior ao relatado por Albuquerque et al. (2005) em um Luvissolo Hipocrômico, no município de Sumé-PB. Estes autores encontraram erodibilidade de $0,013 \mathrm{Mg} \cdot h \cdot \mathrm{MJ}^{-1} \cdot \mathrm{mm}^{-1}$, classificada por Leprun (1983) como baixa. Denardin (1990) encontrou valores de erodibilidade em Argissolos e Planossolos de 0,004 a 0,031 Mg.h.MJ ${ }^{-1} \cdot \mathrm{mm}^{-1}$, respectivamente. Esses solos têm como característica comum a presença do horizonte B textural.

Considerando o fator topográfico (LS) das áreas em estudo, ambas mostraram um comprimento de rampa (L) de $100 \mathrm{~m}$, variando a declividade da vertente (S) que, para o Planossolo Háplico, foi de 5 e, para o Argissolo VermelhoAmarelo, foi de 3, que, de acordo com Medeiros et al. (2016), é classificado como suave a ondulado. Isto reforça a importância de conservar a topografia dos terrenos, pois solos que estão em locais declivosos apresentam maior tendência a processos erosivos, seja hídrico ou eólico, principalmente em locais que possuam cursos de corpos d'água (Valladares et al., 2012). Isso está relacionado à distribuição espaço-temporal dos eventos de chuva analisados nos dois períodos, tendo em vista que o Período I (1996-2015) possui uma maior série de dados pluviométricos em relação ao Período IV (2011-2015), totalizando 20 e 5 anos de dados de chuva, respectivamente.

A maior perda de solo (A) encontrada nesse estudo para o Planossolo Háplico, foi no Período II (2001-2015), com 5,04 Mg.ha ${ }^{-1}$.ano ${ }^{-1}$ (Figura 3A), que, conforme a classificação da FAO (1967), é considerada uma baixa perda de solo. Entretanto, essa perda de solo foi apenas cerca de $7,00 \%$ maior que Período I. Para o Argissolo Vermelho-Amarelo foi de 2,75 Mg.ha- ${ }^{-1} \mathrm{ano}^{-1}$, classificada como muito baixa (FAO, 1967), também correspondente ao Período II (2001-2015). Esses resultados estão relacionados ao fator $\mathrm{R}$ do Período II, que foi de 420,89 MJ.mm.ha ${ }^{-1} \cdot h^{-1} \cdot$ ano $^{-1}$, sendo ligeiramente superior ao do Período I (393,92 MJ.mm.ha ${ }^{-1} \cdot \mathrm{h}^{-1} \cdot$ ano $\left.^{-1}\right)$. Segundo Schick et al. (2000), a perda de solo está relacionada com a erosividade dos eventos de precipitação e da umidade do solo.

As maiores perdas de solo foram registradas no período de 2001-2015, onde as chuvas foram superiores à média anual $(600,62$ $\mathrm{mm}$ ). Para minimizar as perdas de solo, algumas práticas, como plantio direto, podem ser adotadas para manter a estrutura e melhorar a infiltração da água no solo e, consequentemente, diminuir o escoamento superficial (Schick et al., 2000). A utilização de terraços em locais suscetíveis às perdas de solo auxilia nas práticas conservacionistas, contribuindo para uma diminuição de $73 \%$ das perdas de solo, com relação às condições originais (Chaves, 2010). Esse tipo de solo apresenta altas taxas de perdas de solo devido à baixa resistência à desagregação e ao selamento encontrado na sua superfície (Eltz, Mehl \& Reichert, 2001). Outro fator que pode proporcionar o aceleramento das perdas de solo são os manejos inadequados do solo e o uso excessivo das terras (Medeiros et al., 2016).

Os Planossolos são solos mais suscetíveis à erodibilidade, causando maiores perdas de solo; isso pode estar relacionado à sua elevada resistência à penetração, baixa infiltração, altas concentrações abruptas de argila no horizonte B e um horizonte coeso (Santos et al., 2013; Almeida, Souza \& Corrêa, 2016). As tomadas de decisão para a utilização das terras e o bom manejo do solo são fatores importantíssimos para que não ocorram perdas de solo e consequências negativas para o meio ambiente (Lambin, Geist \& Lepers, 2003). Outro fator importante é a análise da série de dados pluviométricos na estimativa de perdas de solo através da USLE.

\section{Conclusão}

A aplicação do método da USLE foi satisfatória na constatação de diferentes perdas de solo, em função dos dados de séries provisórias de chuva para o município de Serra Talhada, PE.

O Planossolo Háplico e o Argissolo Vermelho-Amarelo apresentaram baixa tolerância à perda de solo, considerando as condições edafoclimáticas da região, sendo as perdas de solo do primeiro tipo sempre superiores ao longo dos anos.

\section{Agradecimentos}

Os autores agradecem a todos que compõem o Grupo de Agrometeorologia no Semiárido-GAS, à Agência Pernambucana de Águas e Clima-APAC pela disponibilidade dos dados meteorológicos e à Universidade Federal Rural de Pernambuco-UFRPE, Unidade Acadêmica de Serra Talhada-UAST pela disponibilidade de suas instalações.

\section{Referências}

ALBUQUERQUE, A. W. MOURA FILHO, G.; SANTOS, J. R.; COSTA, J. P. V.; SOUZA, J. L. 2005. Determinação de fatores da equação universal de perda de solo em Sumé, PB. Revista 
Brasileira de Engenharia Agrícola e Ambiental, v. 9, n. 2, p. 153-160.

ALMEIDA, J. D. M.; SOUZA, J. O. P.; CORRÊA, A. C. B. 2016. Dinâmica e caracterização fluvial da bacia do riacho grande, Serra Talhada - PE: Abordagem da conectividade da paisagem. Geo UERJ, v. 1, n. 28, p. 308-331.

ALVARES, C. A.; STAPE, J. L.; SENTELHAS, P. C.; GONÇALVES, J. L. M.; SPAROVEK, G. 2013. Köppen's climate classification map for Brazil. Meteorologische Zeitschrift, v. 22, n. 6, p. 711-728.

AMARAL, B. S. D. 2016. Análise espacial das perdas de solo no estado da Paraíba. Monografia (Bacharelado em Geografia) Universidade Federal da Paraíba. João Pessoa, Brasil. 57p.

BARROS, P. P. S.; FIORIO, P. R.; MARTINS, J. A.; DEMATTE, J. A. M. 2016. Comparison between use and occupancy and soil loss, in the years 1995 and 2010, in the Ceveiro watershed. Revista Ambiência, v. 12, n. 2, p. 513-523.

BERTONI, J.; LOMBARDI NETO, F. 2012. Conservação do solo. 8. ed. São Paulo: Ícone.

CAMPOS FILHO, O. R.; SILVA, I. F.; ANDRADE, A. P.; LEPRUN, J. C. 1992. Erosividade da chuva e erodibilidade do solo no Agreste de Pernambuco. Pesquisa Agropecuária Brasileira, v. 27, n. 9, p. 1363-1370.

CARVALHO, N. O. 2008. Hidrossedimentologia prática. 2. ed. Revisado e Ampliado. Rio de Janeiro: Interciência.

CHAVES, H. M. L. 2010. Incertezas na predição da erosão com a USLE: impactos e mitigação. Revista Brasileira de Ciência do Solo, v. 34, n. 1, p. 2021-2029.

DENARDIN, J. E. 1990. Erodibilidade de solo estimada por meio de parâmetros físicos e químicos. Tese de Doutorado em Agronomia Solos e Nutrição de Plantas, Escola Superior de Agricultura Luiz de Queiroz, Universidade de São Paulo, Piracicaba, Brasil. 81p.

ELTZ, F. L. F.; MEHL, H. U.; REICHERT, J. M. 2001. Perdas de solo e água em entres sulcos em um Argissolo Vermelho-Amarelo submetido a quatro padrões de chuva. Revista Brasileira de Ciência do Solo, v. 25, n. 2, p. 485-493.
FAO-Food and Agriculture Organization of the United Nations. 1967. La erosion del suelo por el água: Algunas medidas para combatirla en las tierras de cultivo. Roma: Organización de Las Naciones Unidas.

FIORIO, P. R.; BARROS, P. P. S.; OLIVEIRA, J. S.; NANNI, M. R. 2016. Estimates of soil loss in a GIS environment using different sources of topographic data. Revista Ambiência, v. 12, n. 1, p. 203-216.

GUERRA, A. J. T.; SILVA, A. S.; BOTELHO, R. G. M. 2009. Erosão e conservação dos solos: conceitos, temas e aplicações. 4. ed. Rio de Janeiro. Bertand Brasil.

GUIMARÃES, C. C. B.; VALLADARES, G. S.; MARTINS, C. M. 2016. Uso das terras e declividade no Sertão central do Ceará, Brasil. Revista Nordestina de Biologia, v. 24, n. 1, p. 3-18.

LAMBIN, E. F.; GEIST, H. J.; LEPERS, E. 2003. Dynamics of land-use and land-cover change in tropical regions. Annual Review of Environment and Resources, v. 28, n. 1, p. 205-241.

LEPRUN, J. C. 1983. Relatório de fim de convenio de manejo e conservação do solo no Nordeste brasileiro (1982-1983). Recife: SUDENE DRN.

LOMBARDI NETO, F.; MOLDENHAUER, W. C. 1992. Erosividade da chuva: sua distribuição e relação com as perdas de solo em Campinas (SP). Bragantia, v. 51, n. 2, p. 189-196.

MANNIGEL, A. R.; CARVALHO, M. P.; MORETI, D.; MEDEIROS, L. R. 2002. Fator erodibilidade e tolerância de perda dos solos do Estado de São Paulo. Acta Scientiarum. Agronomy, v. 24, n. 5, p. 1335-1340.

MEDEIROS, G. O. R.; GIAROLLA, A.; SAMPAIO, G.; MARINHO, M. A. 2016. Estimates of annual soil loss rates in the state of São Paulo, Brazil. Revista Brasileira de Ciência do Solo, v. 40, n. 1, p. 1-18.

OLIVEIRA, F. P.; SANTOS, D.; SILVA, I. F.; SILVA, M. L. N. 2008. Tolerância de perda de solo por erosão para o Estado da Paraíba. Revista de Biologia e Ciências da Terra, v. 8, n. 2, p. 60-71.

OLIVEIRA, P. T. S.; WENDLAND, E.; NEARING, M. A. 2012. Rainfall erosivity in Brazil: A review. Catena, v. 100, n. 1, p. 139-147. 
PEREIRA, P. C.; SILVA, T. G. F.; ZOLNIER, S.; MORAIS, J. E. F.; SANTOS, D. C. 2015. Morfogênese da palma forrageira irrigada por gotejamento. Revista Caatinga, v. 28, n. 3, p. 184195.

R CORE TEAM. R. 2016. A language and environment for statistical computing. $\mathrm{R}$ Foundation for Statistical Computing, Vienna, Austria.

SANTOS, H. G.; JACOMINE, P. K. T.; ANJOS, L. H. C.; OLIVEIRA, V. A.; LUMBRERAS, J. F.; COELHO, M. R.; ALMEIDA, J. A.; CUNHA, T. J. F.; OLIVEIRA, J. B. 2013. Sistema Brasileiro de Classificação de Solos. 3. ed. rev. e ampl. Brasília: Embrapa.

SANTOS, T. E. M.; SILVA, D. D.; MONTENEGRO, A. A. A. 2010. Temporal variability of soil water content under different surface conditions in the semiarid region of the Pernambuco State. Revista Brasileira de Ciência do Solo, v. 34, n. 5, p. 1733-1741.

SCHICK, J.; BERTOL, I.; BATISTELA, O.; BALBINOT JÚNIOR, A. A. 2000. Erosão hídrica em Cambissolo Húmico alumínico submetido a diferentes sistemas de preparo e cultivo do solo: I. Perdas de Solo e Água. Revista Brasileira de Ciência do Solo, v. 24, n. 2, p. 427-436.

SILVA, A. M.; ALVARES, C. A. 2005. Levantamento de informações e estruturação de um banco de dados sobre a erodibilidade de classes de solos no Estado de São Paulo. Geociências, v. 24, n. 1, p. 33-42.

SILVA, B. B.; FERREIRA, M. A. F.; SILVA, V. P. R.; FERREIRA, R. C. 2010. Desempenho de modelo climático aplicado à precipitação pluvial do Estado de Pernambuco. Revista Brasileira de Engenharia Agrícola e Ambiental, v. 14, n. 4, p. 387-395.

SILVA, T. G. F.; PRIMO, J. T. A.; MOURA, M. S. B.; SILVA, S. M. S.; MORAIS, J. E. F.; PEREIRA, P. C.; SOUZA, C. A. A. 2015. Soil water dynamics and evapotranspiration of forage cactus clones under rainfed conditions. Pesquisa Agropecuária Brasileira, v. 50, n. 7, p. 515-525.

THOMAZ, E. L. 2009. The influence of traditional steep land agricultural practices on runoff and soil loss. Agriculture, Ecosystems and Environment, v. 130, n. 1, p. 23-30.

VALLADARES, G. S.; GOMES, A. S.; TORRESAN, F. E.; RODRIGUES, C. A. G.; GREGO, C. R. 2012. Modelo multicritério aditivo na geração de mapas de suscetibilidade à erosão em área rural. Pesquisa Agropecuária Brasileira, v. 47, n. 9 , p. 1376-1383.

WISCHMEIER, W. H.; SMITH, D. D. 1978. Predicting rainfall erosion losses: a guide to conservation planning. Washington: USDA. Agricultural Handbook, 537p. 